\title{
O JAPÃO VISTO DE PORTUGAL EXPLORAÇÃO USANDO UM CORPO DE TEXTOS JORNALÍSTICOS
}

\author{
LUÍS FERNANDO COSTA
}

\section{A BS T R AC T}

The Portuguese were the first Europeans establishing contact with Japan in the 16 th century. They wrote about what they had seen there, which was the start of a long history of documenting Japan in Portugal. Even though the relationship between the two countries had its ups and downs throughout the times, fascination for Japan among the Portuguese seems to continue.

The goal of the study reported in this article was to identify which aspects of Japan most drawn the attention of Portuguese media in the 90s. Concordances and frequencies from the CETEMPúblico corpus, containing texts published in the Portuguese daily newspaper PÚBLICO in the 90s, and a combination of automatic and manual processes, were used for that purpose.

\section{[1] IN TR O D U Ç Ã O}

Os portugueses chegaram ao Japão no ano de 1543, causando uma impressão tão forte nos japoneses que ainda hoje se podem observar os resultados desse encontro entre culturas tão diversas. As influências mais evidentes encontram-se na alimentação e na própria língua japonesa.

O tempura, um dos pratos mais famosos da cozinha japonesa foi introduzido pelos portugueses no Japão (é uma adaptação do prato português peixinhos da horta). De referir também a adaptação do bolo pão de ló em que a versão japonesa se chama kasutera e do kompeito (em Portugal, confeito) em que as versões adaptadas no Japão serão nesta altura mais populares que os «originais» em Portugal.

Relativamente à língua japonesa, diversas palavras comuns provêm do português. Alguns exemplos são pan (pão), koppu (copo), shabon (sabão) e tabako (tabaco).

O fascínio foi recíproco; a obra Historia de Japam (Fróis 1976-1984) escrita pelo português Luís Fróis no século XVI relata com tal pormenor a época em que viveu que ainda hoje é uma fonte muito utilizada mesmo por investigadores japoneses.

Outro português que escreveu sobre o Japão foi João Rodrigues, que escreveu uma gramática muito completa da língua japonesa (Rodrigues 1604), para além de outras obras, relatando a história do Japão e as suas observações sobre diferentes aspetos da cultura japonesa como a pintura, a arquitetura, regras de cortesia 
e a cerimónia do chá. Escreveu também sobre ciência, nomeadamente sobre os conhecimentos de matemática e astronomia no Japão.

Mais recentemente, outro português enamorou-se perdidamente pelo Japão: Wenceslau de Moraes. No final do século XIX, princípio do século XX, escreveu vários livros, descrevendo o povo japonês com uma profundidade inigualável à época (de Moraes 1993). Viveu trinta anos no Japão, no final da sua vida, com um estilo de vida muito semelhante aos japoneses. Morreu mesmo no Japão, onde jaz sepultado.

Janeira (1981) e Janeira (1988) são leituras muito interessantes sobre estas temáticas. Nessas obras, fala-se destes e de outros portugueses que ajudaram a trazer Portugal a paragens tão remotas.

Nesses tempos o Japão era um país fechado ao exterior. Mas as coisas mudaram radicalmente desde então. Hoje, muitos de nós, para além de termos produtos japoneses em casa, tivemos também contacto de alguma forma com outras criações japonesas como o Sushi, o Karaoke, o Manga ou o Anime.

Através do trabalho descrito neste artigo, pretendeu-se determinar quais as facetas do Japão que são mais destacadas pelos meios de comunicação social portugueses dos dias de hoje. Analisou-se, para tal, de forma semiautomática um conjunto de textos publicados no jornal Público na década de 90.

\section{[2] METODOLOGIA}

Para realizar o estudo descrito neste artigo, usou-se um sub-conjunto do corpo CETEMPúblico (Rocha \& Santos 2000). Este corpo é um recurso valiosíssimo que contém o texto de cerca de 2.600 edições do jornal diário português PÚBLICO, publicadas entre os anos de 1991 e 1998, totalizando cerca de 180 milhões de palavras. O CETEMPúblico está dividido em 1.504.258 extratos, classificados por semestre e por assunto.

Cada um destes extratos está por sua vez dividido em parágrafos e frases, estando também assinalados os seus títulos e autores. Para além de tudo isto, a cada palavra ou átomo (unidade) do corpo encontra-se associada informação gramatical, anotada automaticamente pelo analisador sintático PALAVRAS (Bick 2000). Esta informação inclui a categoria gramatical das palavras, bem como informação morfológica, sintática e semântica.

O objeto do estudo eram especificamente os textos relacionados com o Japão. Para determinar estes textos e, consequentemente, criar um sub-corpo de textos relacionados com o Japão, selecionaram-se todos os extratos de texto contendo pelo menos uma das seguintes palavras: Japão, as várias formas do lema japonês (japonês, japonesa, japoneses e japonesas) e do lema nipónico (nipónico, nipónica, nipónicos e nipónicas). Concluiu-se, então, que 24.673 dos extratos continham uma destas palavras e, portanto, podem estar de alguma forma relacionados com o Japão. 
Os trabalhos de análise de conteúdo de textos em português que consegui encontrar são feitos sobre amostras bem mais pequenas. Veja-se, por exemplo, Ferro (2011), Lobo (2010) e Magalhães (2004) onde se estudaram respetivamente 161, 159 e 73 peças jornalísticas, e de Almeida Menezes (2011), onde se estudaram 10 entrevistas. Apenas em Magalhães (2004) e de Almeida Menezes (2011) é indicado terem-se utilizado ferramentas computacionais para suportar a análise do conteúdo dos textos. Em ambos os casos foram usadas ferramentas do WordSmith Tools (Scott 1996). Em Lobo (2010) é referido explicitamente não se terem usado programas de computador para suportar a análise textual e em Ferro (2011) não é feita qualquer referência ao seu uso.

Para outras línguas existem variados exemplos do uso de ferramentas computacionais para suportar a análise de quantidades muito maiores de texto. Vejase, por exemplo, Kutter \& Kantner (2012), onde se trabalhou sobre um corpo de meio milhão de textos em inglês, holandês, francês e alemão para analisar como os meios de comunicação social de diferentes países europeus cobrem guerras e intervenções militares, e Baker et al. (2008) onde se usaram textos em inglês contendo 140 milhões de palavras para estudar como a imprensa britânica relata assuntos relacionados com refugiados, pessoas que pediram asilo, imigrantes e migrantes.

Para o trabalho descrito neste artigo, dada a quantidade de texto e a abrangência do objeto de estudo, usou-se uma mistura de processos computacionais e manuais. Relativamente aos processos computacionais, utilizaram-se fundamentalmente concordâncias e distribuições. Tanto umas como outras podem ser obtidas através do serviço de interrogação a corpos AC/DC (Costa et al. 2009). Este serviço permite fazer pesquisas num conjunto de corpos com diferentes características, sendo o CETEMPúblico um desses corpos.

Concordâncias não são mais do que exemplos extraídos de um corpo de textos que correspondem a uma determinada expressão de pesquisa. Por exemplo, interrogando-se o corpo CETEMPúblico no AC/DC com a expressão de pesquisa [sem="93b" \& word="Soares"] (esta expressão indica que se pretendem todas as ocorrências da palavra Soares no segundo semestre de 1993), obtêm-se 2.176 concordâncias, incluindo os seguintes exemplos.

(1) par=ext53093-pol-93b-2: Antes da assinatura do protocolo, pelo presidente da Câmara de Usuki, Toshio Shibasaki, e pelo comissário-geral da Comissão dos Descobrimentos, Vasco Graça Moura, já Mário Soares prometera às cerca de duas mil pessoas que se deslocaram ao centro da cidade que Portugal tudo fará para fazer do Museu Namban-Centro de Documentação das Relações Luso-Nipónicas «um grande museu de amizade Portugal-Japão» . 
(2) par=ext82501-pol-93b-1: Os originais deverão ser entregues ao imperador Akihito antes de 18 de Outubro, data em que se inicia a visita oficial ao Japão do Presidente da República, Mário Soares .

(3) par=ext111822-pol-93b-1: Soares respondeu que não se mostrava nada impressionado com a mensagem, pois acabava precisamente de chegar de óptimos momentos de convívio com um imperador - o do Japão .

As distribuições, tal como as concordâncias, referem-se a expressões de pesquisa. Mas em vez de exemplos, os resultados são apresentados através de contagens. Exemplificando, veja-se a figura 1, onde se pode observar o resultado de um pedido de distribuição por assunto dos extratos relacionados com o Japão. Os extratos incluídos no CETEMPúblico estão classificados por assunto, tendo esta classificação sido determinada automaticamente a partir da secção do jornal de onde cada extrato é proveniente. As categorias utilizadas para classificar o assunto dos extratos são as seguintes: Sociedade, Política, Desporto, Cultura, ND (não determinado), Economia, Opinião e Informática. Para detalhes sobre como esta classificação foi feita, pode consultar o artigo Rocha \& Santos (2000).

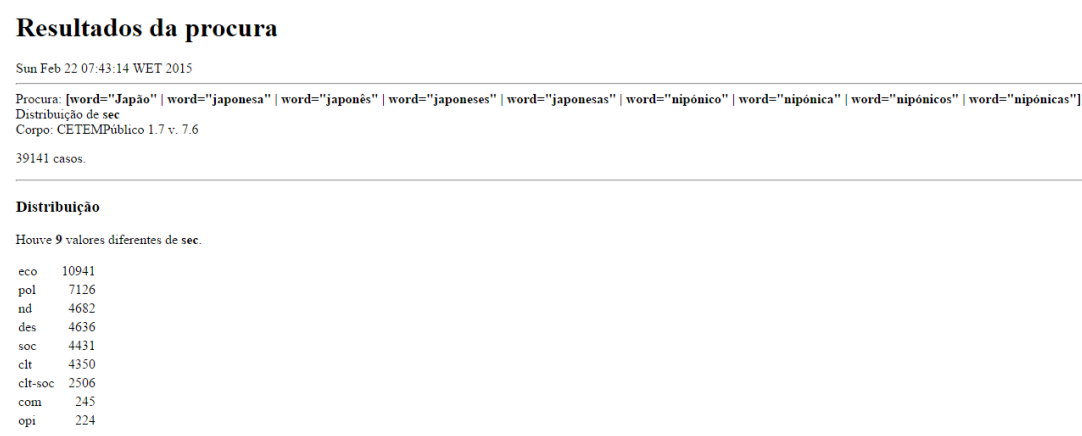

FIGURA 1: Distribuição por assunto no AC/DC

Tal como referido anteriormente, o primeiro passo deste trabalho, foi criar um sub-corpo do CETEMPúblico contendo os extratos de texto relacionados com o Japão. Determinou-se então, a distribuição destes extratos por semestre e por assunto.

Seguidamente, identificaram-se as personalidades que aparecem com maior frequência nos extratos usando-se a anotação morfológica contida no CETEMPúblico. Com base nesta anotação, geraram-se listas com o número de extratos em que ocorre cada uma das palavras marcadas como nome próprio. Isto foi feito para a globalidade do sub-corpo de extratos relacionados com o Japão e para cada um dos semestres abrangidos pelo mesmo. Da lista ordenada pelo número de extratos em que cada um dos nomes próprios ocorre, extraíram-se então as quinze personalidades mais citadas. 
Partindo destes resultados, analisaram-se manualmente extratos onde essas personalidades são nomeadas para determinar o motivo pelo qual estas aparecem com maior ou menor frequência ao longo do tempo. Esta análise foi feita usando concordâncias obtidas através do serviço AC/DC. Para além disso foram também consultadas fontes externas, como por exemplo a Wikipédia. Diga-se que esta análise manual dos extratos foi feita de forma bastante ligeira e pouco sistemática. Estou convencido que também aqui se poderão automatizar partes do processo, e pretendo investigar as melhores formas de o fazer em trabalhos futuros.

\section{[3] RESULTADOS}

Começou-se por contabilizar o número de extratos que referem de alguma forma o Japão em cada um dos semestres abrangidos pelo estudo. Como se pode constatar na figura 2, a percentagem de extratos referindo temas japoneses varia entre os $1,2 \%$ e os $2,1 \%$. O semestre com mais referências a temas japoneses foi o segundo semestre de 1993. Possivelmente, isto deveu-se às mudanças políticas ocorridas por essa altura no Japão: o Partido Liberal Democrata, que tinha governado o Japão ininterruptamente desde 1955, foi destronado no decorrer desse semestre.

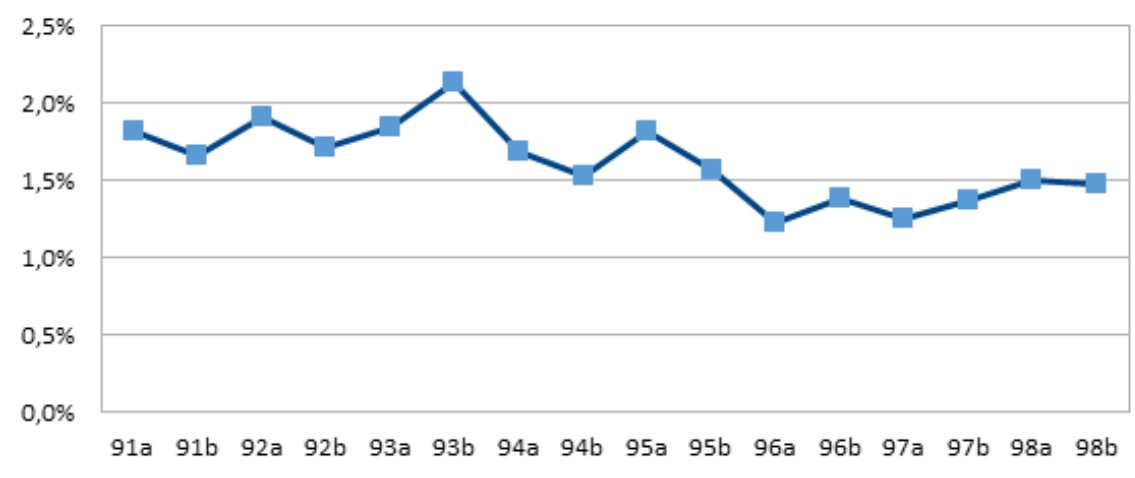

FIGURA 2: Percentagem de extratos relacionados com o Japão

Como referido anteriormente, os extratos no corpo CETEMPúblico estão classificados por assunto. Na figura 3 pode consultar a percentagem de extratos pertencentes a cada uma das categorias. Refira-se que, relativamente ao ano de 1991, uma percentagem muito significativa dos extratos não está classificada e, portanto, não se podem tirar grandes conclusões.

De qualquer modo, pode-se constatar que existe alguma variação de semestre para semestre no que diz respeito às categorias mais representadas. Os extratos mais frequentes são sobre economia e pode-se verificar que, na maior parte dos semestres, esses são os extratos em maior quantidade. As exceções são (para além do ano de 1991, relativamente ao qual não se podem tirar grandes conclu- 
sões, como referido anteriormente) o segundo semestre de 1993, onde os extratos sobre política são os mais numerosos (devido às já referidas mudanças políticas históricas) e o primeiro semestre de 1995, onde os extratos em maior quantidade são os classificados como sociedade (isto deveu-se a dois acontecimentos trágicos: um sismo devastador em Kobe e o ataque com o gás venenoso sarin no Metro de Tóquio).

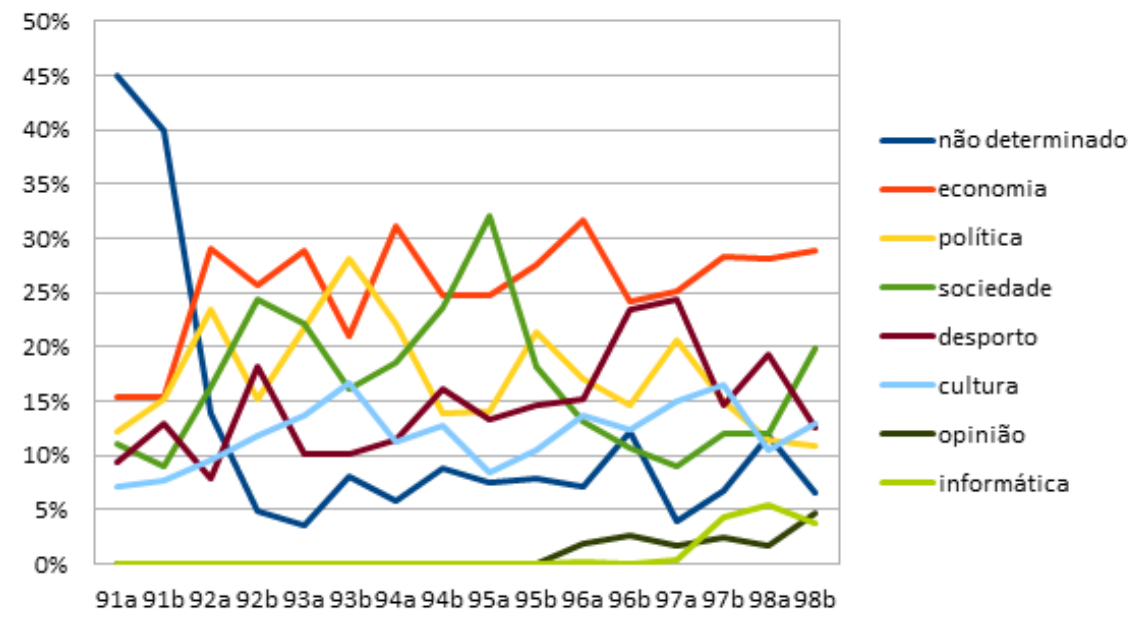

FIGURA 3: Distribuição dos assuntos dos extratos relacionados com o Japão

De forma a entender do que tratavam os vários extratos referentes ao Japão incluídos no CETEMPúblico, contabilizaram-se os nomes de pessoas neles contidos. As figuras 4,5 e 6 resumem os resultados obtidos. Os gráficos apresentam o número de extratos por semestre em que cada um dos nomes é referido. A figura 4 inclui as personalidade japonesas, ao passo que a figura 6 refere-se às personalidades internacionais nos extratos com menções ao Japão. Considerou-se conveniente incluir um gráfico separado (figura 5) para duas personalidades japonesas (o realizador de cinema Akira Kurosawa e o Imperador Akihito). O motivo desta separação prende-se com o facto de estas duas personalidades serem referidas ao longo de todo o período de estudo, ao passo que as pessoas incluídas na figura 4 são referidas muitas vezes em determinados semestres, mas 'desaparecem do radar' no resto do período de estudo.

\section{[3.1] Personalidades japonesas}

Como seria de esperar, nove das quinze pessoas mais referidas nos extratos estudados são personalidades japonesas. É de referir também que todas estas personalidades são homens, sendo a maior parte deles, na realidade, os vários primeirosministros que o Japão teve entre 1991 e 1998. 


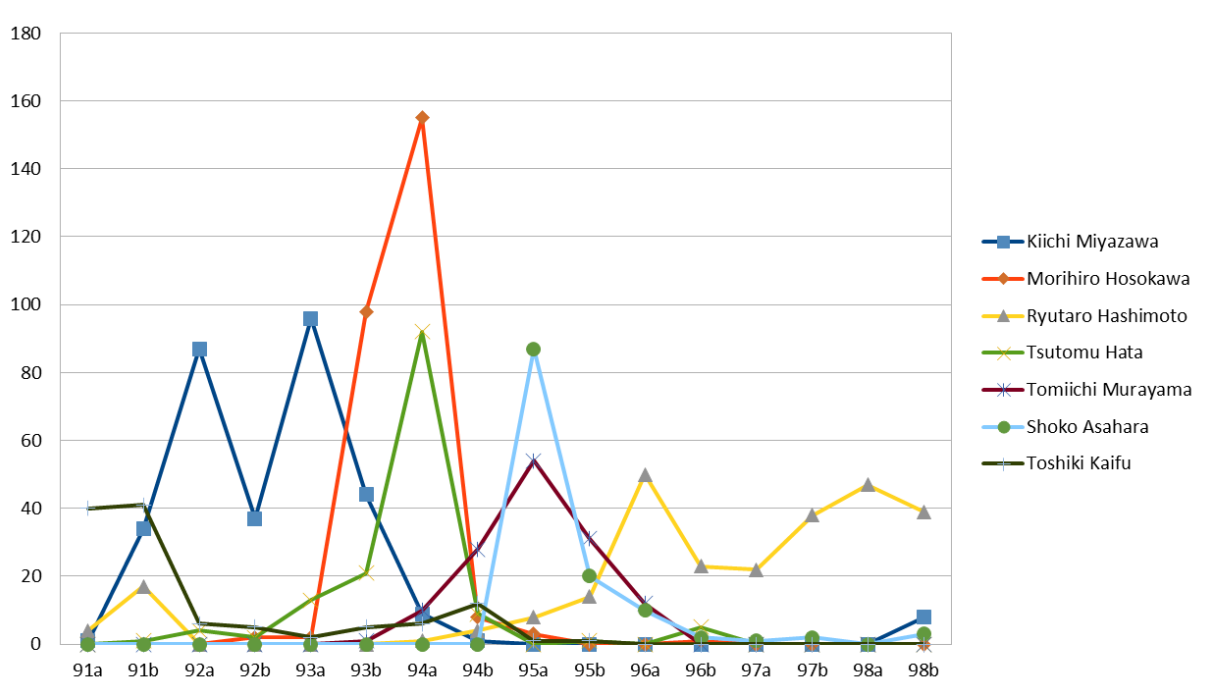

FIGURA 4: Referências a personalidades japonesas

Toshiki Kaifu foi primeiro-ministro entre Agosto de 1989 e Novembro de 1991. As referências ao seu nome aparecem maioritariamente durante a porção desse período coberta pelo corpo CETEMPúblico, o ano de 1991. Depois disso, o seu nome aparece apenas esporadicamente. Surge no entanto um ligeiro aumento de ocorrências no segundo semestre de 1994, que se deve à criação do partido político Partido da Nova Fronteira, do qual foi o primeiro presidente. Depois desse semestre, no entanto, o seu nome praticamente deixa de ser referido.

O seu sucessor no cargo de primeiro-ministro, Kiichi Miyazawa, ocupou o cargo de Novembro de 1991 a Agosto de 1993. É, aliás, a personalidade japonesa mais referida no corpo CETEMPúblico e, como seria de esperar, a maior parte dessas referências ocorre no período em que foi primeiro-ministro. Depois desse período, o seu nome deixa de ser referido quase de todo, aparecendo apenas algumas referências no segundo semestre de 1998, aquando da sua nomeação como ministro das finanças do governo liderado por Keizo Obuchi.

O primeiro-ministro que se seguiu, Morihiro Hosokawa, que ocupou o cargo entre Agosto de 1993 e Abril de 1994, tem o maior número de referências num único semestre de entre todas as personalidades japonesas estudadas. Isto devese a ter liderado a coligação que destronou o Partido Liberal Democrata, que tinha governado o Japão ininterruptamente desde 1955. Para o grande número de referências no primeiro semestre de 1994 contribuíram, também, as suas tentativas de melhorar as relações com os países vizinhos e a sua demissão, provocada pelas acusações de corrupção de que foi alvo. 
Depois da demissão de Hosokawa, Tsutomu Hata ocupou o cargo de primeiroministro por umas breves nove semanas, entre Abril e Junho de 1994. A maior parte das referências ao seu nome no corpo CETEMPúblico surgem, portanto, no primeiro semestre de 1994, mas existem algumas referências em 1993, por ter fundado o partido Shinseito, que fez parte da coligação que apoiou o governo liderado por Hosokawa. Foi também ministro dos negócios estrangeiros desse mesmo governo desde Agosto de 1993 até à sua tomada de posse como primeiro-ministro.

Seguiu-se Tomiichi Murayama, que foi primeiro-ministro entre Junho de 1994 e Janeiro de 1996. O maior número de referências ao seu nome surge no primeiro semestre de 1995, isto porque o Japão esteve em foco internacionalmente devido a dois acontecimentos trágicos: o devastador sismo em Kobe, a 17 de Janeiro, e o ataque com gás sarin (uma arma química muito potente) no Metro de Tóquio, a 20 de Março.

O sucessor de Murayama no cargo de primeiro-ministro foi Ryutaro Hashimoto. Ele ocupou o cargo entre Janeiro de 1996 e Julho de 1998. No entanto, existem referências ao seu nome já desde 1991, dado ter sido o ministro das finanças do governo Kaifu em 1991 e o ministro da economia do governo Murayama entre 1994 e 1996.

A outra personalidade incluída na figura 4 é Shoko Asahara. Ele foi o fundador do grupo religioso Verdade Suprema, tristemente famoso por vários dos seus seguidores terem feito ataques com gás sarin no Metro de Tóquio que causaram a morte de 12 pessoas e um grande número de feridos. Como se pode observar no gráfico, foi o nome mais referido no semestre em que ocorreu o ataque, o primeiro semestre de 1995.

Como referido anteriormente, o gráfico que se pode observar na figura 5, contém a distribuição por semestre das referências a duas outras personalidades japonesas, Akira Kurosawa e o Imperador Akihito.

As referências a Kurosawa surgem na sua maior parte nos anos de 1991, 1992 e 1993. Foi no decorrer desse período que ele realizou os seus dois últimos filmes: Rapsódia em Agosto, em 1991, e Madadayo, em 1993. No segundo semestre de 1995, surgem algumas referências devido a um ciclo de cinema japonês exibido no cinema Nimas, em Lisboa. O ciclo incluía filmes de Kurosawa, mas os seus filmes foram também citados pela crítica especializada ao comentar filmes de outros realizadores. Finalmente, no segundo semestre de 1998, o número de referências ao realizador volta a aumentar, porque foi nessa altura que ele faleceu.

$\mathrm{O}$ imperador Akihito surge com alguma frequência no segundo semestre de 1993, por um lado, por ter feito uma visita à Europa e, por outro lado, por ter recebido o presidente português Mário Soares, que visitou o Japão nessa altura. Mas o período em que o imperador aparece mais vezes no corpo CETEMPúblico é no primeiro semestre de 1998, em que é relatada a sua visita a Portugal, acompanhado da imperatriz Michiko, aquando da Exposição Mundial em Lisboa (Expo-98). 


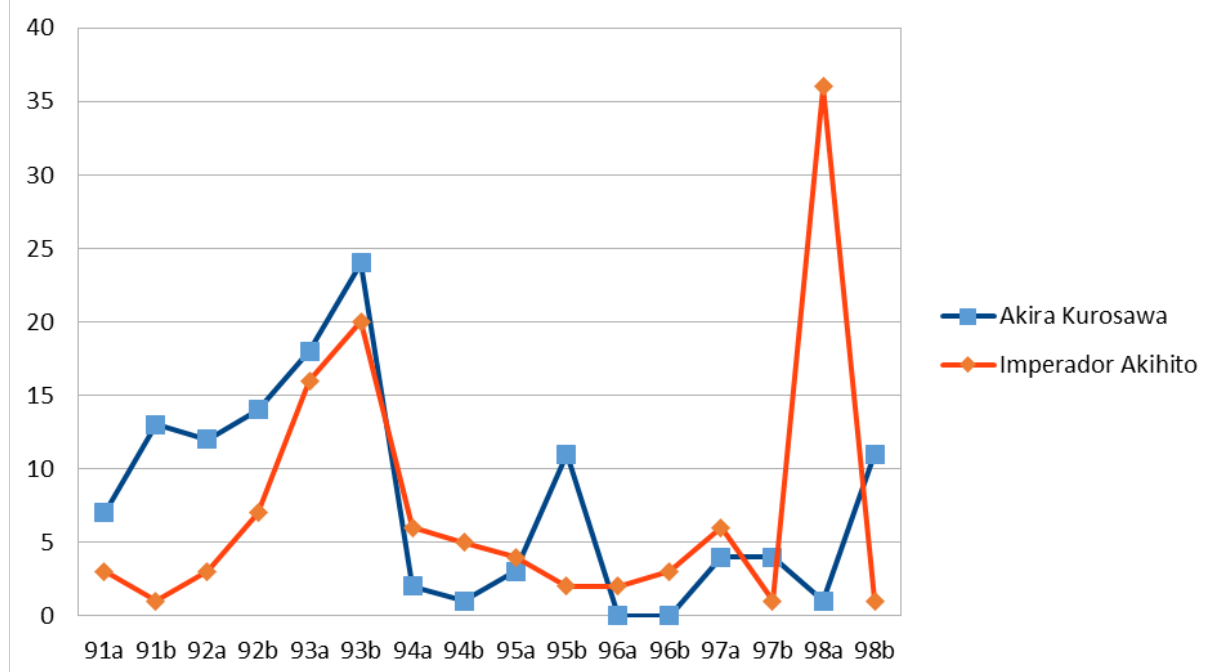

FIGURA 5: Referências a Kurosawa e ao Imperador Akihito

\section{[3.2] Personalidades internacionais}

De entre as quinze personalidades mais referidas nos artigos estudados do CETEMPúblico, seis delas não são japonesas. Há dois presidentes dos Estados Unidos (George Bush e Bill Clinton), o à data presidente da Rússia, Boris Ieltsin, e o presidente português da altura Mário Soares. Finalmente, a completar o rol, temos duas personalidades do mundo do desporto motorizado: o piloto de Fórmula 1 Michael Schumacher e o motociclista Michael Doohan.

Os Estados Unidos são parceiros muito importantes do Japão, tanto a nível comercial, como militar, pelo que é natural que as personalidades internacionais mais citadas nos artigos referentes ao Japão sejam os presidentes americanos Bush e Clinton.

George Bush foi o presidente dos Estados Unidos entre Janeiro de 1989 e Janeiro de 1993. As referências ao seu nome no corpo concentram-se, por isso, nos textos publicados entre 1991 e 1993, e ocorrem mais vezes no primeiro semestre de 1992. Isto deve-se ao facto de Bush ter feito uma visita de estado ao Japão nesse semestre.

Foi sucedido no cargo por Bill Clinton, que foi presidente dos Estados Unidos até 2001. Bill Clinton é mais referido no primeiro semestre de 1993, que coincide com os seus primeiros meses na presidência. O início do seu mandato foi marcado por uma série de medidas económicas protecionistas que tiveram impacto no Japão, e isso contribuiu para o seu nome aparecer muitas vezes nos textos relacionados com este país. Outro fator determinante foi uma visita aos Estados Unidos feita pelo primeiro-ministro japonês Miyazawa, que se encontrou com Clinton. As 
referências a Clinton estendem-se por todo o período de estudo, havendo, no entanto, um aumento de volume no primeiro semestre de 1996. Isto deve-se à visita que fez ao Japão por essa altura, e durante a qual se encontrou com o primeiroministro japonês Hashimoto.

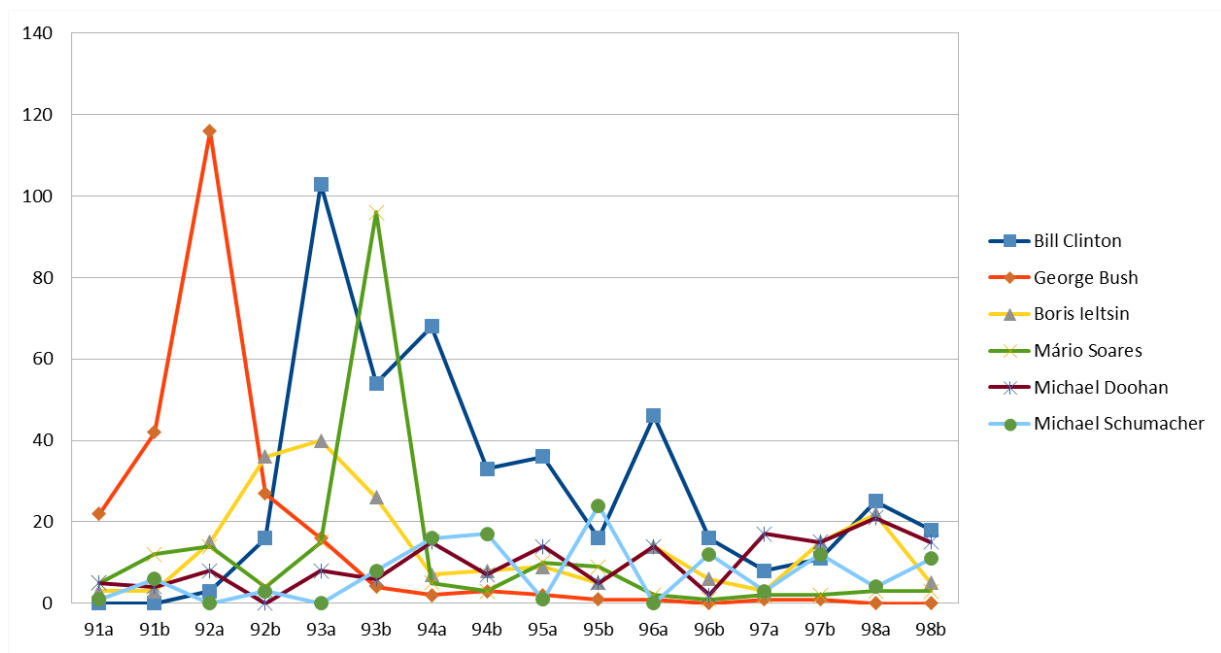

FIGURA 6: Referências a personalidades internacionais

Boris Ieltsin foi o presidente da Rússia de Julho de 1991 a Dezembro de 1999, ou seja, a sua presidência estendeu-se por quase todo o período abrangido pelos textos estudados neste artigo. Ieltsin aparece mais vezes relacionado com o Japão no segundo semestre de 1992 e no ano de 1993. No que diz respeito a 1992, esse protagonismo deveu-se às dificuldades diplomáticas entre a Rússia e o Japão, que levaram inclusive ao cancelamento de uma visita de Ieltsin a este país. Nessa altura, a Rússia enfrentava graves dificuldades económicas e necessitava criticamente de financiamento, mas o Japão fazia depender esse financiamento da resolução do conflito entre os dois países relativo às ilhas Curilhas. Estas ilhas foram ocupadas pelo exército soviético no final da Segunda Grande Guerra. Relativamente a 1993, a Rússia (e o seu presidente Ieltsin) aparecem frequentemente nos artigos sobre o Japão devido à cimeira do G7 (grupo englobando os países mais economicamente desenvolvidos do mundo), realizada em Tóquio entre 7 e 9 de Julho. A Rússia, à data, não fazia parte do grupo, e causou sensação ter sido convidada a fazê-lo pelo Japão, que liderava o G7 na altura.

Mário Soares foi presidente de Portugal de Março de 1986 a Março de 1996. A sua ligação ao Japão deve-se principalmente à sua visita àquele país em Outubro de 1993. A maior parte das referências ao seu nome aparecem, portanto, nos textos publicados no segundo semestre desse ano. Nesse semestre foi mesmo a personalidade internacional mais referida nos extratos estudados, tendo quase o mesmo 
número de referências que a personalidade japonesa mais citada, o primeiroministro Hosokawa.

Analisando-se extratos onde são nomeados os dois pilotos incluídos na lista dos quinze nomes mais referidos nos textos estudados do CETEMPúblico (Michael Doohan e Michael Schumacher), percebe-se que estes não têm nenhuma ligação particular ao Japão. Os seus nomes aparecem em extratos contendo a palavra Japão porque existem Grandes Prémios do Japão, tanto em motociclismo, como em Fórmula 1. Para além disso, Michael Doohan correu por uma marca japonesa, a Honda, havendo também vários pilotos japoneses nas provas de motociclismo em que ele participou. Decorre daí que o seu nome ocorra com alguma frequência em textos contendo as palavras nipónico, nipónica, japonês e japonesa.

\section{[4] OBSERVAÇÕES FINAIS}

No trabalho descrito neste artigo usou-se uma abordagem semiautomática para analisar textos sobre o Japão publicados no jornal PÚBLICO. Começou-se por selecionar de forma automática, de entre todos os extratos de texto incluídos no CETEMPúblico, aqueles que estão relacionados com o Japão. Para tal, usou-se como critério de escolha, a presença de determinadas palavras-chave nos extratos. Seguidamente, determinou-se a distribuição dos textos selecionados por semestre e por tema. O passo seguinte foi identificar as personalidades que neles aparecem com maior frequência. Partindo desses resultados analisaram-se manualmente extratos onde essas personalidades são nomeadas para determinar porque estas aparecem com maior ou menor frequência ao longo do tempo. Frequentemente os resultados desta análise acabaram por revelar os acontecimentos relacionados com o Japão que mais captaram a atenção dos jornalistas portugueses.

A distribuição de extratos por assunto revelou uma maior abundância de textos sobre economia. Isto não surpreende dado que o Japão é uma das maiores economias do mundo, produzindo e exportando inúmeros produtos para todo o mundo. Os únicos semestres em que os textos sobre economia não dominaram foram o segundo semestre de 1993 (ano em que o Partido Liberal Democrata perdeu as eleições depois de inúmeros anos no poder) e o primeiro semestre de 1995, em que ocorreu um grande sismo em Kobe e o ataque com gás sarin no Metro de Tóquio.

No que diz respeito às personalidades referidas nos textos, refira-se que todas as quinze pessoas mais referidas são homens, sendo nove deles japoneses. Seis das personalidades japonesas são os vários primeiros-ministros que governaram o Japão durante o período de estudo (como se pode constatar, foi um período de alguma instabilidade política). Adicionalmente fazem parte desta lista o Imperador Akihito, o realizador Akira Kurosawa e o líder da seita Verdade Suprema Shoko Asahara. 
Relativamente às seis personalidades internacionais mais citadas nos textos relacionados com o Japão, concluiu-se que duas delas são desportistas que não têm nenhuma ligação particular ao Japão. Os restantes foram presidentes das duas superpotências mundiais, os Estados Unidos e a Rússia, e o presidente português Mário Soares.

A metodologia utilizada neste trabalho, inclui uma fase em que textos são analisados manualmente para tentar determinar as razões da notoriedade das personalidades neles mencionadas variar ao longo do tempo. Dada a quantidade de textos existentes, esta análise foi necessariamente feita de forma ligeira e pouco sistemática. Em trabalhos futuros pretendo investigar como se poderá estender o suporte computacional também a esta fase da análise dos textos.

Outras áreas que pretendo explorar no futuro são as ocorrências de outros nomes próprios como locais e marcas, e a comparação de resultados com outros corpos, como por exemplo um corpo de português brasileiro como o CETENFolha, outro dos corpos que se pode pesquisar usando o AC/DC.

Finalmente, também pretendo investigar o processo oposto, ou seja estudar as referências a Portugal nos meios de comunicação social japoneses.

\section{AGRADECIMENTOS}

Estou agradecido à Diana por me ter desafiado a escrever este artigo e principalmente por me ter dado a oportunidade de começar a trabalhar para a Linguateca em 2002. Para além de ter aprendido imenso, conheci muitas pessoas interessantes, entre elas a homenageada neste livro, a Belinda, com a qual também tive o prazer de trabalhar.

\section{REFERENCIAS}

de Almeida Menezes, Danielle. 2011. Discurso sobre literaturas de língua inglesa: uma análise baseada em ferramentas da linguística de Corpus. Trabalhos em Linguística Aplicada 50(1). 97-118.

Baker, Paul, Costas Gabrielatos, Majid Khosravinik, Michal Krzyzanowski, Tony McEnery \& Ruth Wodak. 2008. A useful methodological synergy? Combining critical discourse analysis and corpus linguistics to examine discourses of refugees and asylum seekers in the UK press. Discourse and Society 19(3). 273-305.

Bick, Eckhard. 2000. The Parsing System "Palavras": Automatic Grammatical Analysis of Portuguese in a Constraint Grammar Framework: Aarhus University. Tese de Doutoramento.

Costa, Luís, Diana Santos \& Paulo Alexandre Rocha. 2009. Estudando o português tal como é usado: o serviço AC/DC. Em The 7th Brazilian Symposium in Information and Human Language Technology (STIL 2009), 150-153. 
Ferro, Hugo. 2011. A construção mediática da saúde mental e da doença mental: o caso do Público e do Correio da Manhã entre 1990 e 2010: Faculdade de Letras da Universidade de Coimbra. Tese de Mestrado.

Fróis, Luís. 1976-1984. Historia de Japam. Biblioteca Nacional de Lisboa. 5 volumes. Edição anotada por José Wicki.

Janeira, Armando Martins. 1981. Figuras de Silêncio -- A Tradição Cultural Portuguesa no Japão de Hoje. Junta de Investigações Científicas do Ultramar.

Janeira, Armando Martins. 1988. O Impacto Português sobre a Civilização Japonesa. Publicações Dom Quixote 2nd edn.

Kutter, Amelia \& Cathleen Kantner. 2012. Corpus-Based Content Analysis: A Method for Investigating News Coverage on War and Intervention. International Relations Online Working Paper. Stuttgart University. http://www . uni-stuttgart.de/soz/ib/forschung/IRWorkingPapers/ IROWP_Series_2012_1_Kutter_Kantner_Corpus-Based_Content_ Analysis.pdf.

Lobo, Mafalda. 2010. Cobertura mediática de África na imprensa europeia, no contexto da II Cimeira UE-África. http://www.bocc.uff.br/pag/ silva-mafalda-cobertura-mediatica-de-africa-na-imprensa-europeia. pdf.

Magalhães, Célia. 2004. Interdiscursividade e conflito entre discursos sobre raça em reportagens brasileiras. Linguagem em (Dis)Curso 4. 35-60.

de Moraes, Wenceslau. 1993. Antologia. Vega. Selecção de textos de Armando Martins Janeira.

Rocha, Paulo \& Diana Santos. 2000. CETEMPúblico: Um corpus de grandes dimensões de linguagem jornalística portuguesa. Em Maria das Graças Volpe Nunes (ed.), Actas do $V$ Encontro para o processamento computacional da língua portuguesa escrita e falada (PROPOR), 131-140.

Rodrigues, João. 1604. Arte da Lingoa de Iapam. Collegio de Iapão da Companhia de Iesu.

Scott, Mike. 1996. Wordsmith tools. Oxford University Press.

CONTACTOS

Luís Fernando Costa

Yamaguchi University e Linguateca

luis.f.kosta@gmail.com 